\title{
Irritable Bowel Syndrome: Manipulating the Endocannabinoid System as First-Line Treatment
}

\author{
Viola Brugnatelli ${ }^{1 *}$, Fabio Turco ${ }^{2}$, Ulderico Freo $^{3}$ and Gastone Zanette ${ }^{1}$ \\ ${ }^{1}$ Department of Neuroscience, University of Padua, Padua, Italy, ${ }^{2}$ Molecular Biology and Biochemistry Lab, Department of \\ Neurogastroentherology, University of Naples Federico II, Naples, Italy, ${ }^{3}$ Department of Medicine, University of Padua, \\ Padua, Italy
}

Keywords: IBS, endocannabinoid, CB1, CB2, TRPV1, THC, CBD, PEA

\section{INTRODUCTION}

Irritable Bowel Syndrome (IBS) is a functional disorder characterized by abdominal pain, spasms, and altered bowel movements, either predominantly diarrhea (IBS-D), or predominantly constipation (IBS-C), or alternating between those states (Saha, 2014). In the Western world it affects the $10-15 \%$ of the population (Canavan et al., 2014). IBS represents a visceral hypersensitivity, with features of gastrointestinal (GI) allodynia and hyperalgesia. Considered a life-long condition, it is clear that significant gastrointestinal insults, such as food poisoning

OPEN ACCESS

Edited by: Rajeev K. Singla,

Sichuan University, China

Reviewed by:

Vipan K. Parihar,

University of California, Irvine,

United States

Marcus Scotti,

Federal University of Paraíba, Brazil

${ }^{*}$ Correspondence:

Viola Brugnatelli

viola.brugnatelli@unipd.it

Specialty section: This article was submitted to

Neuropharmacology,

a section of the journal

Frontiers in Neuroscience

Received: 19 December 2019 Accepted: 26 March 2020

Published: 21 April 2020

Citation:

Brugnatelli V, Turco F, Freo $U$ and Zanette G (2020) Irritable Bowel

Syndrome: Manipulating the

Endocannabinoid System as First-Line Treatment. Front. Neurosci. 14:371.

doi: 10.3389/fnins.2020.00371 or antibiotic administration, may generate attacks that persist, often indefinitely. Attacks are associated with anxiety and depression, but controversy carries on to which incites the other (Saha, 2014). It is possible that some patients may develop a vicious cycle of worsening physical and psychological symptoms (Jones et al., 2013, 2017).

Currently, IBS sufferers are prescribed opioids, anticholinergics, and antidepressants, however with quite suboptimal results. Other compounds have been formulated to interact with serotoninergic circuitry, nevertheless these have been withdrawn from certain markets due to association with ischemic colitis (alosetron, cilansetron) and cardiovascular events (tegaserod), leaving, de facto, an urgent clinical need (Ford et al., 2014; Lexicomp Online, 2017).

The Endocannabinoid System (ECS) is known to modulate several functions, including mood, anxiety, and memory retrieval of traumatic events and it directly coordinates GI propulsion, secretion, inflammation, and nociception, providing a rationale for agents capable of interacting with the ECS as treatment candidates for IBS (Russo, 2016).

\section{IRRITABLE BOWEL SYNDROME AND THE ENDOCANNABINOID SYSTEM}

\section{Endocannabinoid System in the Bowel}

The ECS is ubiquitously expressed in the human body and it actively controls gut homeostasis. The best characterized ECS receptors are the cannabinoid receptors 1 (CB1) and 2 (CB2) (Mackie, 2005).

CB1 has been found in intestinal epithelial and in the enteric nervous system (ENS) (Coutts and Izzo, 2004).

Physiologically, the activation of presynaptic CB1 attenuates large and small bowel muscle tone and inhibits GI motility, mainly by reducing the release of acetylcholine from enteric nerves and also by inhibiting all the components of the peristaltic reflex (Wright et al., 2005). Moreover, CB1 activation, via the purinergic system, inhibits spontaneous ileal contractions and modulate the activity of vagal neurotransmission, reducing intestinal peristalsis (DiPatrizio, 2016). 
CB2 has been found on enteric neurons but it is predominantly expressed by intestinal immune cells (Izzo, 2007). Targeting intestinal CB2 decreases inflammation through the reduction of cytokine and chemokine production from activated immune cells (Wright et al., 2008). In pathophysiological conditions, CB2 controls intestinal motility (Wright et al., 2008) and its activation slows down gut transit (Mathison et al., 2004).

Bot 1 and CB2 have been identified in the intestinal neuronal circuitry of the transmission of visceral pain and their activation reduce visceral sensation and nociception (Hohmann and Suplita, 2006).

$\mathrm{N}$-arachidonoylethanolamine (anandamide, AEA) and 2-arachidonoyl glycerol (2-AG) are the best characterized endocannabinoids; they are synthesized from membrane phospholipids on demand: AEA is synthesized by $\mathrm{N}$-acylphosphatidylethanolamine phospholipase D (NAPE-PLD); and 2-AG by diacylglycerol lipase (DAGL), then they are released and induce a local response by activating CB1 and/or CB2 receptors (the latter being involved mainly in pathophysiological conditions) (Izzo and Camilleri, 2008). These compounds are involved in the control of food intake and hunger (DiPatrizio, 2016; Lee et al., 2016). Specifically, AEA seems to regulate appetite and energy balance, while 2-AG may serve as a general hunger signal (Di Marzo and Matias, 2005; DiPatrizio, 2016). AEA, via CB2, plays also a pivotal role in maintaining immunological health in the gut (Acharya et al., 2017).

Subsequent to their activation, endocannabinoids are inactivated by reuptake from the degradative enzymes fatty acid amide hydrolase (FAAH), located in cells of the myenteric plexus and monoacylglycerol lipase (MAGL), present in the nerve cells and fibers throughout the muscle mucosal layers of the intestine (Di Marzo, 2006).

Inhibition of MAGL and FAAH in the gut significantly reduces experimental colitis in mice, through mechanisms that involve a rise in 2-AG or AEA levels, respectively, and the stimulation of both CB1 CB2 signaling (Massa et al., 2004; Sałaga et al., 2014; Vera and Fichna, 2017).

$\mathrm{N}$-palmitoylethanolamine (PEA) and other $\mathrm{N}$ acylethanolamides (NAEs) are also expressed in the gut (Izzo and Sharkey, 2010). NAEs are atypical endocannabionoids: their structures resemble the classical endocannabinoids and they are preferentially metabolized by FAAH, but they do not bind CB receptors (Izzo and Sharkey, 2010; Ahn et al., 2014). NAEs, especially PEA, are involved in the control of various functions, including food intake, neuroprotection, nociception, and inflammation (Suardíaz et al., 2007; Ahn et al., 2014; Lowin et al., 2015).

Other components of the ECS are the transient receptor potential (TRP) channels, such as TRPV1, TRM8, and others (Storozhuk and Zholos, 2018). These receptors, widely expressed throughout the digestive tract, are involved in numerous processes: taste, chemo- and mechanosensation, thermoregulation, pain and hyperalgesia, mucosal function, gut homeostasis, and control of motility, amongst others (Kaneko and Szallasi, 2014).

GPR55, another potential cannabinoid receptor, seems to be also implicated in gut motility. Its inhibition reduce motility in mice and this effect was reversed by cannabidiol (CBD), but not by CB1 or CB2 receptor antagonists (Li et al., 2013).

The ECS is also an important modulator of the gut-brain axis. In the gut, receptors of the ECS (especially TRPs) are involved in sensory transduction of a large number of external and noxious stimuli (Holzer, 2011). In the brain, the ECS controls nausea and vomiting, especially through $\mathrm{CB} 1$ receptors in the dorsal vagal complex of the brainstem, and stress-induced alterations of the ECS have been linked to altered visceral sensations (Sharkey and Wiley, 2016).

The main role of ECS in the GI tract is controlling intestinal hyper-contractility. Moreover, it modulates visceral sensations, intestinal inflammation and gut-brain communications, all functions that appear to be dysregulated in IBS.

\section{IBS and Endocannabinoid Deficiency}

Clinical Endocannabinoid Deficiency (CED) has been confirmed as a plausible feature in a series of difficult-to-characterize psychosomatic pathologies, which display hyperalgesia, anxiety, and depression (Russo, 2004, 2016); Migraine, fibromyalgia and IBS fall in this category, often showing comorbidity in the three diagnosis (Nicolodi and Sicuteri, 1996; Sperber et al., 1999; Peres et al., 2001). CED occurs either as a congenital disorder, or as a result of epigenetic changes.

IBS subtypes exhibit distinct variations of the ECS tone. IBSD patients show genetic alterations affecting endocannabinoid metabolism, variants of the CNR1 and FAAH genes, and lower levels of Oleoylethanolamine (OEA) and PEA compared to healthy subjects (Fichna et al., 2013). Specifically, the CNRI rs806378 CT/TT genotype shows a significant association with colonic transit in IBS-D (Camilleri et al., 2013). Conversely, IBS$\mathrm{C}$ patients show levels of OEA higher than healthy volunteers, and reduced levels of FAAH mRNA in intestinal tissues (Fichna et al., 2013).

Some of these changes may occur as the result of chronic stress, which profoundly impacts the ECS: it silences the Cnr1 gene promoter via an increased methylation by DNA (cytosine5)-methyltransferase 1, but it also activates the Trpv1 promoter via acetylation (Hong et al., 2015). This results in reduced levels of CB1 and increased levels of TRPV1 in the sensory neurons localized in the pelvic organs, including the colon, which is a feature of visceral pain, as later discussed (Fichna et al., 2013).

Stress in the early-life stage is also an important contributor to IBS development and it is associated with epigenetic changes that lead to visceral hypersensitivity (Moloney et al., 2015). Maternal deprivation increases the expression of the endocannabinoid genes Cnr1, Cnr2a, Cnr2b, and GPR55 in the frontal cortex of male rats, whereas in female rats, increased expression was reported only in the hippocampus, a difference that may underline the prevalence of IBS in the female population (Marco et al., 2014). The relevance of pediatric stress in IBS is supported by the fact that infantile colitis, characterized by visceral sensitivity and dysphoria and resistant to most pharmacotherapies, seem to be offset by the endocannabinoids present in maternal milk, reason for it is hypothesized that this condition may also be a CED (Russo, 2004). Taken these data together, genetic polymorphisms and alterations in gene 


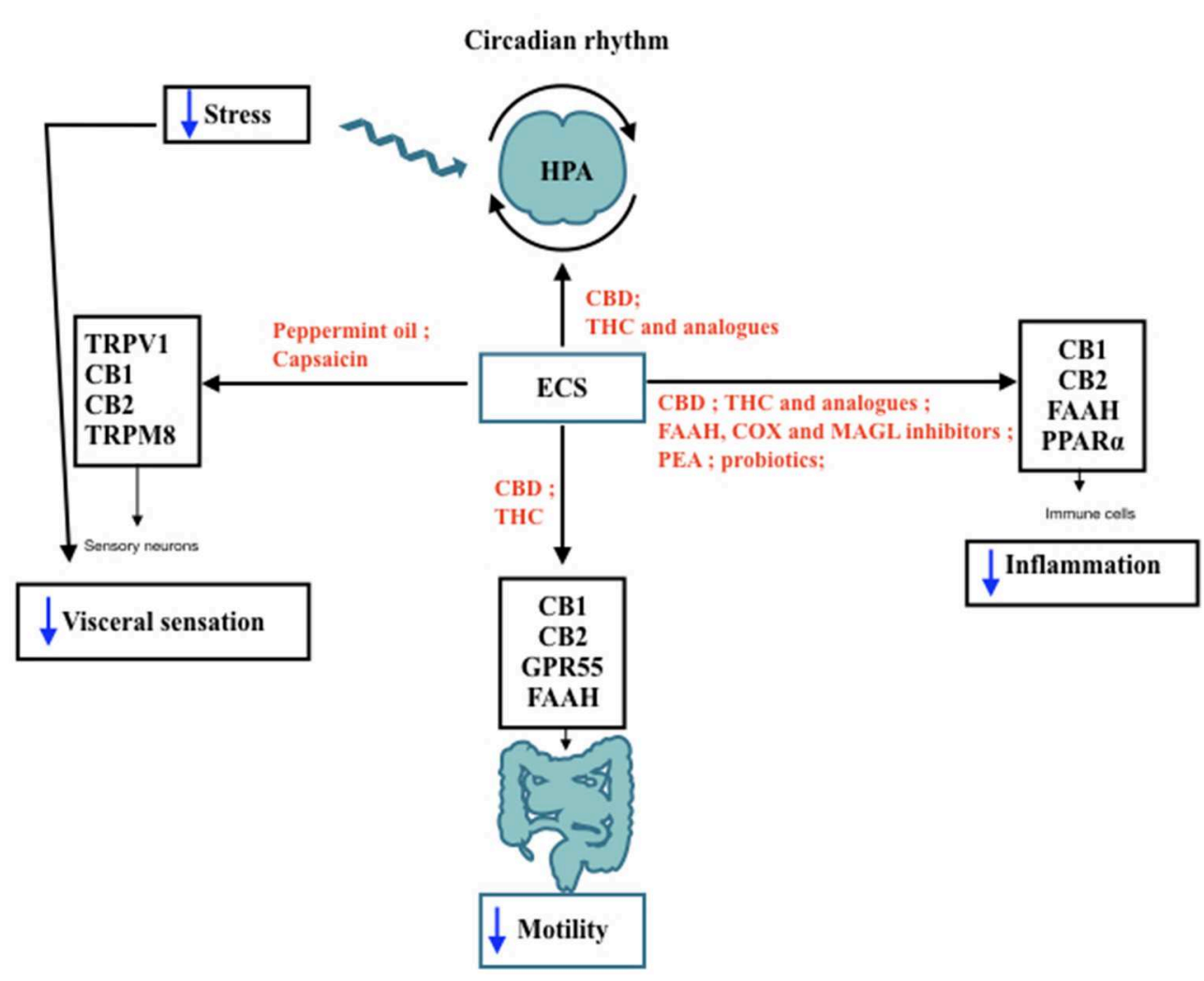

FIGURE 1 | IBS features modulated by ECS. Schematic representation of the Endocannabinoid System (ECS) involvement in IBS features and its interaction with hypothalamic-pituitary-adrenal (HPA) axis throughout day/night. The black arrows indicate the receptors and the target sites controlled by ECS components. In red are shown the agents capable of modulating ECS activities that may be useful to improve IBS symptoms, such as motility, visceral pain, and low-grade inflammation. Blue arrows indicate a decrease in the functions targeted by ECS stimulation. TRPV I, Transient receptor potential vanilloid I; CB I, Cannabinoid Receptor I; CB2:

Cannabinoid Receptor 2; TRPM8, Transient receptor potential melastatin 8; CBD, cannabidiol; THC, tetrahydrocannabinol; FAAH, fatty acid amide hydrolase; COX, cyclooxigenase; MAGL, monoacyl glycerol lipase; PEA, palmitoylethanolamide; PPARa: Peroxisome proliferator-activated receptor a.

expression are associated with disturbances in GI motility and sensation, supporting the pathophysiologic significance of alterations in the ECS in the gut (Moloney et al., 2015).

\section{UTILIZING ECS-MODULATING AGENTS FOR IBS}

\section{ECS-Modulating Agents}

Gut health devoid of pain and maintenance of balanced body weight seems to require a complex interplay between diet, enteric flora, and endocannabinoid balance (Clarke et al., 2012; Russo, 2016). Oral administration of Lactobacillus acidophilus NCFM induce a direct increase of the cannabinoid receptors CNR2 mRNA (Rousseaux et al., 2007). This result corresponded with an enhancement of morphine analgesic effect in rats, which was inhibited by administration of the CB2 antagonist, AM-630 (Rousseaux et al., 2007). Cannabinoids may also directly alter the microfloral balance, as underscored by the finding that THC affected the Firmicutes:Bacteroidetes ratio in obese mice, preventing their weight gain despite a high-fat diet (Cluny et al., 2015).
The interaction of the microbiome-gut-brain axis is highly dependent on hypothalamic-pituitary-adrenal (HPA) stress modulation, which is dysregulated in IBS patients (Chang et al., 2009). The ECS regulates basal and circadian HPA axis activation (Patel et al., 2004; Liedhegner et al., 2014), and these changes relate to the differences in visceral sensation that feature in IBS (Gschossmann et al., 2001). Linkage of the cannabinoidvanilloid pathway to the HPA axis has been demonstrated by experiments monitoring rats inoculated with corticosterone, mimicking chronic stress, which developed visceral hyperalgesia (Hong et al., 2011); moreover, as also shown by another stressed rat model (Hong et al., 2009), the levels of AEA and the expression and phosphorylation of TRPV1 increased in the animals, whilst CB1 expression decreased in lumbosacral primary afferent neurons localized in the colon, but not in those innervating the lower extremities (Hong et al., 2009, 2011). AEA is an endogenous agonist at both CB1 and TRPV1 (McPartland et al., 2007), receptors that co-localize in nociceptive primary sensory neurons (Ahluwalia et al., 2000). Activation of CB1 inhibits nociception, whereas agonism at TRPV1 increases pain perception (Malik et al., 2015). Treatment of stressed rats with the CB1 agonist WIN 55,212-2 or the TRPV1 antagonist capsazepine 
prevented visceral hyperalgesia (Hong et al., 2009). Similar data have been observed in biopsies from IBS sufferers, which show a 3.5-fold elevation in TRPV1-immunoreactive nerve fibers (Akbar et al., 2008).

Considering this evidences, it has been posited that chronic stress causes down-regulation or loss of CB1, activation of the HPA stress response, anxiety, and induces visceral hyperalgesia that involve region-specific changes in endovanilloid and endocannabinoid pathways in sensory neurons innervating the pelvic viscera (Morena et al., 2016). Thus, a rationale exists for the use of compounds that boost AEA and PEA levels and desensitize TRPV1, to treat hypersensitivity and pain in IBS. While some authors have encouraged the use of the phytocannabinoid cannabidiol (CBD), no clinical trials have tested this hypothesis (Russo, 2004; Pandey et al., 2020). CBD may be an useful therapeutic intervention as it desensitizes TRPV1 and inhibits PEA and AEA hydrolysis and uptake (Bisogno et al., 2001).

Targeting endocannabinoid-degrading enzymes to increase AEA may be an interesting model (Sakin et al., 2015), given their role in the tonic disinhibition of periaqueductal gray region of the brainstem to promote analgesia and chronic stress-induced anxiety (Lau et al., 2014; Sakin et al., 2015). A dual FAAH and COX inhibitor has been shown to increase AEA and PEA levels, reducing features of colitis in mice (Sasso et al., 2015).

\section{Clinical Trials With ECS-Acting Agents}

Despite the numerous lines of evidence showing the involvement of ECS in the regulation of IBS features and the promising data from pre-clinical studies, few clinical trials tested the effect of ECS-modulating agents in IBS.

On the other hand, ECS alteration in IBS patients has been clearly documented.

As ECS is known to decrease motility, effects of dronabinol, a non-selective agonist of the cannabinoid receptors, have been tested on IBS patients (Wong et al., 2011). In a 2011 clinical trial, dronabinol reduced fasting colonic motility in all IBS-D patients, particularly those carrying the CB1 receptor polymorphism rs806378 (Wong et al., 2011). Another clinical study carried out a few years later, failed to replicate these results, obtaining only modest delay in motility, maybe for differences in methods (manometry vs. radioscintigraphy) and the lower number of patients enrolled (Wong et al., 2012). Dronabinol can also improve visceral sensitivity and colonic relaxation, as showed in a double-blind, placebo-controlled trial (Esfandyari et al., 2007).

As mentioned before, Fichna et al. showed that lower PEA levels are associated with cramping abdominal pain (Fichna et al., 2013). A randomized placebo-controlled multicenter study assessing the efficacy of PEA in IBS, revealed that PEA may be an useful tool for pain management in this condition (Barbara et al., 2014).

Since visceral hypersensitivity is linked to an increase in Ts regard, a 2011 pilot study found that ingesting capsaicin-containing enteric-coated pills desensitized TRPV1 and decreased the intensity of abdominal pain and bloating in IBS patients vs. placebo (Bortolotti and Porta, 2011). Another study confirmed that TRPV1 desensitization reduced visceral hypersensitivity, symptoms, and abdominal pain (Wouters et al., 2016).

Menthol-induced analgesia and pain relief is mediated mainly by TRPM8 (Liu et al., 2013). This is the rationale for various trials that analyzed the efficacy of peppermint oil (containing menthol) in IBS. Even with some limitations mainly due to the delivery system of peppermint oil in the digestive tract, it turned out an effective treatment capable of improving IBS symptoms, especially abdominal pain, even in children suffering IBS (Kline et al., 2001; Cappello et al., 2007; Merat et al., 2010; Cash et al., 2016).

\section{CONCLUSIONS}

Although the pathophysiology of IBS remains unclear, targeting the ECS may represent a promising strategy to modulate gut motility, visceral hyperalgesia, low-grade intestinal inflammation, and gut-brain axis alteration, all features that may improve IBS symptoms onset. It is also evident that both an IBS-diet (Wouters et al., 2016) and a stress-relief practice are required to boost the beneficial effects of any of the agents suggested.

In light of this, agents capable of modulating the ECS may provide a strategy worth attempting even first line treatment for IBS patients (Figure 1). This is due to the fact that compounds such as PEA, CBD and peppermint oil display a very large safety profile and have been proving beneficial to improve IBS symptoms (Halford et al., 2018); PEA, peppermint oil, THC and its synthetic analogs may be recommended in IBS patients to improve abdominal spasms, cramps and visceral pain. THC and CBD may alter ECS-driven response to the pathology. However, there is still a wide gap in the current understanding of IBS mechanism and in the use of cannabis containing both CBD and THC as potential therapy, which can only be bridged by randomized clinical trials.

\section{AUTHOR CONTRIBUTIONS}

VB and FT contributed to conception and design of the study and wrote sections of the manuscript. VB wrote the first draft of the manuscript. All authors contributed to manuscript revision, read, and approved the submitted version.

\section{FUNDING}

VB was supported by the grant number is 1973 .

\section{ACKNOWLEDGMENTS}

The authors would like to acknowledge the contribution of Adrian Devitt-Lee, University College of London. 


\section{REFERENCES}

Acharya, N., Penukonda, S., Shcheglova, T., Hagymasi, A. T., Basu, S., and Srivastava, P. K. (2017). Endocannabinoid system acts as a regulator of immune homeostasis in the gut. Proc Natl Acad Sci, U. S. A. 114, 5005-5010. doi: 10.1073/pnas.1612177114

Ahluwalia, J., Urban, L., Capogna, M., Bevan, S., and Nagy, I. (2000). Cannabinoid 1 receptors are expressed in nociceptive primary sensory neurons. Neuroscience. 100, 685-688. doi: 10.1016/S0306-4522(00)00389-4

Ahn, E. H., Kim, D. W., Shin, M. J., Kim, H. R., Kim, S. M., Woo, S. J., et al. (2014). PEP-1-PEA-15 protects against toxin-induced neuronal damage in a mouse model of Parkinson's disease. Biochim Biophysa Acta. 1840, 1686-1700 doi: 10.1016/j.bbagen.2014.01.004

Akbar, A., Yiangou, Y., Facer, P., Walters, J. R., Anand, P., and Ghosh, S. (2008). Increased capsaicin receptor TRPV1-expressing sensory fibres in irritable bowel syndrome and their correlation with abdominal pain. Gut. 57, 923-929. doi: 10.1136/gut.2007.138982

Barbara, G., Cremon, C., Bellacosa, L., De Giorgio, R., Santos, J., Vicario, M., et al. (2014). 714 randomized placebo-controlled multicenter study on the effect of palmitoyl-ethanolamide and polydatin on immune activation in patients with irritable bowel syndrome. Gastroenterology 146:S-124. doi: 10.1016/S0016-5085(14)60446-7

Bisogno, T., Hanus, L., De Petrocellis, L., Tchilibon, S., Ponde, D. E., Brandi, I., et al. (2001). Molecular targets for cannabidiol and its synthetic analogues: effect on vanilloid VR1 receptors and on the cellular uptake and enzymatic hydrolysis of anandamide. Br J Pharmacol. 134, 845-852. doi: 10.1038/sj.bjp.07 04327

Bortolotti, M., and Porta, S. (2011). Effect of red pepper on symptoms of irritable bowel syndrome: preliminary study. Digest Dis Sci. 56, 3288-3295. doi: 10.1007/s10620-011-1740-9

Camilleri, M., Kolar, G. J., Vazquez-Roque, M. I., Carlson, P., Burton, D. D., and Zinsmeister, A. R. (2013). Cannabinoid receptor 1 gene and irritable bowel syndrome: phenotype and quantitative traits. Am J Physiol Gastrointest Liver Physiol 304:G553-G560. doi: 10.1152/ajpgi.00376.2012

Canavan, C., West, J., and Card, T. (2014). The epidemiology of irritable bowel syndrome. Clin Epidemiol. 6, 71-80. doi: 10.2147/CLEP.S40245

Cappello, G., Spezzaferro, M., Grossi, L., Manzoli, L., and Marzio, L. (2007). Peppermint oil (Mintoil $®)$ in the treatment of irritable bowel syndrome: A prospective double blind placebo-controlled randomized trial. Digest Liver Dis. 39, 530-536. doi: 10.1016/j.dld.2007.02.006

Cash, B. D., Epstein, M. S., and Shah, S. M. (2016). A novel delivery system of peppermint oil is an effective therapy for irritable bowel syndrome symptoms. Digest Dis Sci. 61, 560-571. doi: 10.1007/s10620-015-3858-7

Chang, L., Sundaresh, S., Elliott, J., Anton, P. A., Baldi, P., Licudine, A., et al. (2009). Dysregulation of the hypothalamic-pituitary-adrenal (HPA) axis in irritable bowel syndrome. Neurogastroenterol Motil. 21, 149-159 doi: 10.1111/j.1365-2982.2008.01171.x

Clarke, G., Cryan, J. F., Dinan, T. G., and Quigley, E. M. (2012). Review article: probiotics for the treatment of irritable bowel syndromefocus on lactic acid bacteria. Aliment Pharmacol Ther. 35, 403-413. doi: 10.1111/j.1365-2036.2011.04965.x

Cluny, N. L., Keenan, C. M., Reimer, R. A., Le Foll, B., and Sharkey, K. A. (2015). Prevention of diet-induced obesity effects on body weight and gut microbiota in mice treated chronically with delta9-tetrahydrocannabinol. PLoS ONE 10:e0144270. doi: 10.1371/journal.pone.0144270

Coutts, A. A., and Izzo, A. A. (2004). The gastrointestinal pharmacology of cannabinoids: an update. Curr Opin Pharmacol. 4, 572-579. doi: 10.1016/j.coph.2004.05.007

Di Marzo, V. (2006). Endocannabinoids: synthesis and degradation. In: Reviews of Physiology Biochemistry and Pharmacology (Berlin; Heidelberg: Springer), 1-24. doi: 10.1007/112_0505

Di Marzo, V., and Matias, I. (2005). Endocannabinoid control of food intake and energy balance. Nat Neurosci. 8, 585. doi: 10.1038/nn1457

DiPatrizio, N. V. (2016). Endocannabinoids in the gut. Cannabis Cannabinoid Res. 1, 67-77. doi: 10.1089/can.2016.0001

Esfandyari, T., Camilleri, M., Busciglio, I., Burton, D., Baxter, K., and Zinsmeister, A. R. (2007). Effects of a cannabinoid receptor agonist on colonic motor and sensory functions in humans: a randomized, placebocontrolled study. Am J Physiol Gastrointest Liver Physiol. 293:G137-G145. doi: 10.1152/ajpgi.00565.2006

Fichna, J., Wood, J., Papanastasiou, M., Vadivel, S., Oprocha, P., Sałaga, M., et al. and Storr, M. (2013). Endocannabinoid and CannabinoidLike Fatty Acid Amide Levels Correlate with Pain-Related Symptoms in Patients with IBS-D and IBS-C: A Pilot Study. PLoS ONE, 8: p.e85073. doi: 10.1371/journal.pone.0085073

Ford, A. C., Moayyedi, P., Lacy, B. E., Lembo, A. J., Saito, Y. A., Schiller, L. R., et al. (2014). American College of Gastroenterology monograph on the management of irritable bowel syndrome and chronic idiopathic constipation. Am J Gastroenterol. 109(suppl 1):S2-S26. doi: 10.1038/ajg.2014.187

Gschossmann, J. M., Buenger, L., Adam, B., Liebregts, T., Saller, B., Mann, K., et al. (2001). Diurnal variation of abdominal motor responses to colorectal distension and plasma cortisol levels in rats. Neuro-gastroenterol Motil. 13, 585-589. doi: 10.1046/j.1365-2982.2001.00293.x

Halford, J., Marsh, E., Mazurkiewicz-Beldzinska, M., Gunning, B., Checketts, D., Roberts, C., et al. (2018) Long-term safety and efficacy of cannabidiol (CBD) in patients with lennox-gastaut syndrome (LGS): results from open-label extension trial (GWPCARE5) (P1. 264).

Hohmann, A. G., and Suplita, R. L. 2nd. (2006). Endocannabinoid mechanisms of pain modulation. AAPS J. 8:E693-708. doi: 10.1208/aapsj080479

Holzer, P. (2011). TRP channels in the digestive system. Curr Pharmac Biotechnol. 12, 24-34. doi: $10.2174 / 138920111793937862$

Hong, S., Fan, J., Kemmerer, E. S., Evans, S., Li, Y., and Wiley, J. W. (2009). Reciprocal changes in vanilloid (TRPV1) and endocannabinoid (CB1) receptors contribute to visceral hyperalgesia in the water avoidance stressed rat. Gut. 58, 202-210. doi: 10.1136/gut.2008.157594

Hong, S., Zheng, G., and Wiley, J. W. (2015). Epigenetic regulation of genes that modulate chronic stress-induced visceral pain in the peripheral nervous system. Gastroenterology. 148, 148-57.e7. doi: 10.1053/j.gastro.2014.09.032

Hong, S., Zheng, G., Wu, X., Snider, N. T., Owyang, C., and Wiley, J. W. (2011). Corticosterone mediates reciprocal changes in CB1 and TRPV1 receptors in primary sensory neurons in the chronically stressed rat. Gastroenterology 140:627-37.e4. doi: 10.1053/j.gastro.2010.11.003

Izzo, A. A. (2007). The cannabinoid CB2 receptor: a good friend in the gut. Neurogastroenterol Motil. 19, 704-708. doi: 10.1111/j.1365-2982.2007.00977.x

Izzo, A. A., and Camilleri, M. (2008). Emerging role of cannabinoids in gastrointestinal and liver diseases: basic and clinical aspects. Gut. 57, 1140-1155. doi: 10.1136/gut.2008.148791

Izzo, A. A., and Sharkey, K. A. (2010). Cannabinoids and the gut: new developments and emerging concepts. Pharmacol Therap. 126, 21-38. doi: 10.1016/j.pharmthera.2009.12.005

Jones, M. P., Oudenhove, L. V., Koloski, N., Tack, J., and Talley, N. J. (2013). Early life factors initiate a 'vicious circle' of affective and gastrointestinal symptoms: a longitudinal study. United Euro Gastroenterol, J. 1, 394-402. doi: $10.1177 / 2050640613498383$

Jones, M. P., Tack, J., Van Oudenhove, L., Walker, M. M., Holtman, G., Koloski, N. A., et al. (2017). Mood and anxiety disorders precede development of functional gastrointestinal disorders in patients but not in the population. Clin Gastroenterol Hepatol. 15, 1014-20.e4. doi: 10.1016/j.cgh.2016.12.032

Kaneko, Y., and Szallasi, A. (2014). Transient receptor potential (TRP) channels: a clinical perspective. Br J Pharmacol. 171, 2474-2507. doi: 10.1111/bph.12414

Kline, R. M., Kline, J. J., Di Palma, J., and Barbero, G. J. (2001). Enteric-coated, $\mathrm{pH}$-dependent peppermint oil capsules for the treatment of irritable bowel syndrome in children. J Pediatr. 138, 125-128. doi: 10.1067/mpd.2001.109606

Lau, B. K., Drew, G. M., Mitchell, V. A., and Vaughan, C. W. (2014). Endocannabinoid modulation by FAAH and monoacylglycerol lipase within the analgesic circuitry of the periaqueductal grey. Br JPharmacol. 171, 5225-5236. doi: 10.1111/bph.12839

Lee, Y., Jo, J., Chung, H. Y., Pothoulakis, C., and Im, E. (2016). Endocannabinoids in the gastrointestinal tract. Am J Physiol. 311:G655-G666. doi: 10.1152/ajpgi.00294.2015

Lexicomp Online (2017). Lexi-Drugs. Hudson, OH: Lexi-Comp, Inc. Available online at: http://online.lexi.com (accessed December 10, 2019).

Li, K., Fichna, J., Schicho, R., Saur, D., Bashashati, M., Mackie, K., et al. (2013). A role for O-1602 and G protein-coupled receptor GPR55 in 
the control of colonic motility in mice. Neuropharmacology. 71, 255-263. doi: 10.1016/j.neuropharm.2013.03.029

Liedhegner, E. S., Sasman, A., and Hillard, C. J. (2014). Brain region-specific changes in $\mathrm{N}$-acylethanolamine contents with time of day. J Neurochem. 128, 491-506 doi: 10.1111/jnc. 12495

Liu, B., Fan, L., Balakrishna, S., Sui, A., Morris, J. B., and Jordt, S. E. (2013). TRPM8 is the principal mediator of menthol-induced analgesia of acute and inflammatory pain. PAIN. 154, 2169-2177. doi: 10.1016/j.pain.2013. 06.043

Lowin, T., Apitz, M., Anders, S., and Straub, R. H. (2015). Anti-inflammatory effects of $\mathrm{N}$-acylethanolamines in rheumatoid arthritis synovial cells are mediated by TRPV1 and TRPA1 in a COX-2 dependent manner. Arthr Res Ther. 17, 321. doi: 10.1186/s13075-015-0845-5

Mackie, K. (2005). Distribution of cannabinoid receptors in the central and peripheral nervous system. In: Cannabinoids (Berlin; Heidelberg: Springer), 299-325. doi: 10.1007/3-540-26573-2_10

Malik, Z., Baik, D., and Schey, R. (2015). The role of cannabinoids in regulation of nausea and vomiting, and visceral pain. Curr Gastroenterol Rep. 17, 429. doi: 10.1007/s11894-015-0429-1

Marco, E. M., Echeverry-Alzate, V., López-Moreno, J. A., Gin,é, E., Peñasco, S., and Viveros, M. P. (2014). Consequences of early life stress on the expression of endocannabinoid-related genes in the rat brain. Behav Pharmacol. 25, 547-556. doi: $10.1097 /$ FBP. 0000000000000068

Massa, F., Marsicano, G., Hermann, H., Cannich, A., Monory, K., Cravatt, B. F., et al. (2004). The endogenous cannabinoid system protects against colonic inflammation. J Clin Invest. 113, 1202-1209. doi: 10.1172/JCI200419465

Mathison, R., Ho, W., Pittman, Q. J., Davison, J. S., and Sharkey, K. A. (2004). Effects of cannabinoid receptor-2 activation on accelerated gastrointestinal transit in lipopolysaccharide- treated rats. Br J Pharmacol. 142, 1247-1254 doi: 10.1038/sj.bjp.0705889

McPartland, J. M., Glass, M., and Pertwee, R. G. (2007). Meta-analysis of cannabinoid ligand binding affinity and receptor distribution: interspecies differences. Br J Pharmacol. 152, 583-593. doi: 10.1038/sj.bjp.0707399

Merat, S., Khalili, S., Mostajabi, P., Ghorbani, A., Ansari, R., and Malekzadeh, R. (2010). The effect of enteric-coated, delayed-release peppermint oil on irritable bowel syndrome. Digest Dis Sci. 55, 1385-1390. doi: 10.1007/s10620-009-0854-9

Moloney, R. D., Stilling, R. M., Dinan, T. G., and Cryan, J. F. (2015). Earlylife stress-induced visceral hypersensitivity and anxiety behavior is reversed by histone deacetylase inhibition. Neurogastroenterol Motil. 27, 1831-1836. doi: $10.1111 / \mathrm{nmo} .12675$

Morena, M., Patel, S., Bains, J. S., and Hill, M. N. (2016). Neurobiological interactions between stress and the endocannabinoid system. Neuropsychopharmacology. 41, 80-102. doi: 10.1038/npp.2015.166

Nicolodi, M., and Sicuteri, F. (1996). "Fibromyalgia and migraine, two faces of the same mechanism," in Recent Advances in Tryptophan Research, ed G. A. Filippini (New York, NY: Plenum Press), 373-379. doi: 10.1007/978-1-4613-0381-7_58

Pandey, S., Kashif, S., Youssef, M., Sarwal, S., Zraik, H., Singh, R., et al. (2020). Endocannabinoid system in irritable bowel syndrome and cannabis as a therapy. Complement Therap Med. 48, 2242. doi: 10.1016/j.ctim.2019. 102242

Patel, S., Roelke, C. T., Rademacher, D. J., Cullinan, W. E., and Hillard, C. J. (2004). Endocannabinoid signaling negatively modulates stress-induced activation of the hypothalamic-pituitary-adrenal axis. Endocrinology. 145, 5431-5438 doi: 10.1210/en.2004-0638

Peres, M. F., Young, W. B., Kaup, A. O., Zukerman, E., Silberstein, S. D.,Peres, M. F., Young, W. B., Kaup, A. O., et al. (2001). Fibromyalgia is common in patients with transformed migraine. Neurology. 57, 1326-1328. doi: 10.1212/WNL.57.7.1326

Rousseaux, C., Thuru, X., Gelot, A., Barnich, N., Neut, C., Dubuquoy, L., et al. (2007). Lactobacillus acidophilus modulates intestinal pain and induces opioid and cannabinoid receptors. Nat Med. 13, 35-37. doi: 10.1038/nm1521

Russo, E. B. (2004). Clinical endocannabinoid deficiency (CECD): can this concept explain therapeutic benefits of cannabis in migraine, fibromyalgia, irritable bowel syndrome and other treatment-resistant conditions? Neuroendocrinol Lett. 25, 31-39. doi: 10.1522/cla.roj.let

Russo, E. B. (2016). Clinical endocannabinoid deficiency reconsidered: current research supports the theory in migraine, fibromyalgia, irritable bowel, and other treatment-resistant syndromes. Cannabis Cannabinoid Res. 1, 154-165. doi: $10.1089 /$ can.2016.0009

Saha, L. (2014). Irritable bowel syndrome: pathogenesis, diagnosis, treatment, and evidence-based medicine. World J Gastroenterol. 20, 6759-6773. doi: 10.3748 /wjg.v20.i22.6759

Sakin, Y. S., Dogrul, A., Ilkaya, F., Seyrek, M., Ulas, U. H., Gulsen, M., et al. (2015). The effect of FAAH, MAGL, and Dual FAAH/MAGL inhibition on inflammatory and colorectal distension-induced visceral pain models in Rodents. Neurogastroenterol Motil. 27, 936-944. doi: 10.1111/nmo.12563

Sałaga, M., Mokrowiecka, A., Zakrzewski, P. K., Cygankiewicz, A., Leishman, E., Sobczak, M., et al. (2014). Experimental colitis in mice is attenuated by changes in the levels of endocannabinoid metabolites induced by selective inhibition of fatty acid amide hydrolase (FAAH). J Crohn's Colitis. 8, 998-1009. doi: 10.1016/j.crohns.2014.01.025

Sasso, O., Migliore, M., Habrant, D., Armirotti, A., Albani, C., Summa, M., et al. (2015). Multitarget fatty acid amide hydrolase/cyclooxygenase blockade suppresses intestinal inflammation and protects againstnonsteroidal anti-inflammatory drug-dependent gastro-intestinal damage. FASEB J. 29, 2616-2627. doi: 10.1096/fj.15-270637

Sharkey, K. A., and Wiley, J. W. (2016). The role of the endocannabinoid system in the brain-gut axis. Gastroenterology. 151, 252-266. doi: 10.1053/j.gastro.2016.04.015

Sperber, A. D., Atzmon, Y., Neumann, L., Weisberg, I., Shalit, Y., Abu-Shakrah, M., et al. (1999). Fibromyalgia in the irritable bowel syndrome: studies of prevalence and clinical implications. Am J Gastroenterol. 94, 3541-3546. doi: 10.1111/j.1572-0241.1999.01643.x

Storozhuk, M. V., and Zholos, A. V. (2018). TRP channels as novel targets for endogenous ligands: focus on endocannabinoids and nociceptive signalling. Curr Neuropharmacol. 16, 137-150. doi: 10.2174/1570159X15666170424120802

Suardíaz, M., Estivill-Torrús, G., Goicoechea, C., Bilbao, A., and de Fonseca, F. R. (2007). Analgesic properties of oleoylethanolamide (OEA) in visceral and inflammatory pain. PAIN. 133, 99-110. doi: 10.1016/j.pain.2007.03.008

Vera, G., and Fichna, J. R. (2017). Cannabinoids and effects on the gastrointestinal tract: a focus on motility. In: Handbook of Cannabis and Related Pathologies. Biology, Pharmacology, Diagnosis, and Treatment. 947-57 doi: 10.1016/B978-0-12-800756-3.00114-9

Wong, B. S., Camilleri, M., Busciglio, I., Carlson, P., Szarka, L. A., Burton, D., et al. (2011). Pharmacogenetic trial of a cannabinoid agonist shows reduced fasting colonic motility in patients with nonconstipated irritable bowel syndrome. Gastroenterology. 141, 1638-1647. doi: 10.1053/j.gastro.2011.07.036

Wong, B. S., Camilleri, M., Eckert, D., Carlson, P., Ryks, M., Burton, D., et al. (2012). Randomized pharmacodynamic and pharmacogenetic trial of dronabinol effects on colon transit in irritable bowel syndrome-diarrhea. Neurogastroenterol Motil. 24, 358-e169. doi: 10.1111/j.1365-2982.2011.01874.x

Wouters, M. M., Balemans, D., Van Wanrooy, S., Dooley, J., CibertGoton, V., Alpizar, Y. A., et al. (2016). Histamine receptor H1-mediated sensitization of TRPV1 mediates visceral hypersensitivity and symptoms in patients with irritable bowel syndrome. Gastroenterology. 150, 875-887. doi: 10.1053/j.gastro.2015.12.034

Wright, K., Rooney, N., Feeney, M., Tate, J., Robertson, D., Welham, M., et al. (2005). Differential expression of cannabinoid receptors in the human colon: cannabinoids promote epithelial wound healing. Gastroenterology. 129, 437-453. doi: 10.1053/j.gastro.2005.05.026

Wright, K. L., Duncan, M., and Sharkey, K. A. (2008). Cannabinoid CB2 receptors in the gastrointestinal tract: a regulatory system in states of inflammation. $\mathrm{Br} \mathrm{J}$ Pharmacol. 153, 263-270. doi: 10.1038/sj.bjp.0707486

Conflict of Interest: The authors declare that the research was conducted in the absence of any commercial or financial relationships that could be construed as a potential conflict of interest.

Copyright $\odot 2020$ Brugnatelli, Turco, Freo and Zanette. This is an open-access article distributed under the terms of the Creative Commons Attribution License (CC BY). The use, distribution or reproduction in other forums is permitted, provided the original author(s) and the copyright owner(s) are credited and that the original publication in this journal is cited, in accordance with accepted academic practice. No use, distribution or reproduction is permitted which does not comply with these terms. 